\title{
Encontro e diálogo no poema A flor e a náusea, de Carlos Drummond de Andrade: interfaces com a filosofia de Martin Buber
}

\section{Encounter and dialogue in Carlos Drummond de Andrade's poem The flower and the nausea: interfaces with Martin Buber's philosophy}

\section{Fabrício Lemos da Costa}

Graduação em andamento em Filosofia (2017). Universidade Estadual do Amapá - UEAP. Macapá, AP Brasil.

Bruno José Bezerra Ribeiro

Graduação em Filosofia (2017). Universidade Estadual do Amapá - UEAP. Macapá, AP - Brasil.

Resumo: Este trabalho pretende compreender o encontro como uma categoria filosófica no poema $A$ flor e a náusea, bem como a relação entre solidão, ironia, expectativa e revelação, que se conformam à dimensão ôntica do diálogo apontado pela filosofia de Martin Buber. Através da interface entre estes dois autores, procurou-se uma reflexão fecunda entre poesia e literatura, reconhecendo o âmbito intuitivo como um campo aberto ao "phatos dialógico".

Palavras-chave: Martin Buber; Carlos Drummond de Andrade; Encontro.

Abstract: This work intends to understand the encounter as a philosophical category in the poem The flower and the nausea, as well as the relation between solitude, irony, expectation and revelation, that conform to the ontic dimension of the dialogue pointed out by the philosophy of Martin Buber. Through the interface between these two authors a fruitful reflection between poetry and literature was sought, recognizing the intuitive scope as a field open to "dialogical phatos".

Keywords: Martin Buber; Carlos Drummond de Andrade; Encounter. 
O poema A flor e a náusea, de Carlos Drummond de Andrade, poeta moderno brasileiro, faz parte da coletânea intitulada A rosa do povo, publicada em 1945. A obra insere-se no que os críticos consideram a fase social do poeta, a qual a entendem como uma obra de maturidade. Drummond apresenta uma expressão carregada de ironia e cinismo ao longo da obra, reflexo de um ambiente histórico denso que incorpora conflitos e paradoxos; nela, consciente de suas limitações, o poeta lança-se à incerteza do mundo e de si mesmo.

O poema Aflor e a náusea é um exemplo do conflito de forças polarizadas que lutam por uma síntese, submergindo na interioridade como uma maneira de redescobrir o mundo. A angústia presente neste poema reflete com maestria a densidade do lirismo drummondiano, assim, vemos nele a existência aprisionada na solidão que recai sobre o indivíduo; seu ego fragmentado é vítima de um mundo também despedaçado, cercado de relações reificadas, a qual o poeta sintomatiza em tédio e enjoo. No entanto, outra forma se faz notar, crescendo, um encontro com a forma autêntica, escondida pela exterioridade, na paradoxal revelação de uma forma feia, em meio ao tumulto do mundo. A autenticidade aqui é encontrada na forma de uma flor.

Ei-lo transcrito na íntegra:

A FLOR E A NÁUSEA

Preso à minha classe e a algumas roupas, vou de branco pela rua cinzenta.

Melancolias, mercadorias espreitam-me.

Devo seguir até o enjôo?

Posso, sem armas, revoltar-me?

Olhos sujos no relógio da torre:

Não, o tempo não chegou de completa justiça.

O tempo é ainda de fezes, maus poemas, alucinações e espera.

O tempo pobre, o poeta pobre

fundem-se no mesmo impasse.

Em vão me tento explicar, os muros são surdos.

Sob a pele das palavras há cifras e códigos.

O sol consola os doentes e não os renova.

As coisas. Que tristes são as coisas, consideradas sem ênfase.

Vomitar esse tédio sobre a cidade.

Quarenta anos e nenhum problema

resolvido, sequer colocado.

Nenhuma carta escrita nem recebida.

Todos os homens voltam para casa.

Estão menos livres mas levam jornais

e soletram o mundo, sabendo que o perdem.

Crimes da terra, como perdoá-los?

Tomei parte em muitos, outros escondi.

Alguns achei belos, foram publicados.

Crimes suaves, que ajudam a viver.

Ração diária de erro, distribuída em casa.

Os ferozes padeiros do mal.

Os ferozes leiteiros do mal.

Pôr fogo em tudo, inclusive em mim.

Ao menino de 1918 chamavam anarquista.

Porém meu ódio é o melhor de mim. 
Com ele me salvo

e dou a poucos uma esperança mínima.

Uma flor nasceu na rua!

Passem de longe, bondes, ônibus, rio de aço do tráfego.

Uma flor ainda desbotada

ilude a polícia, rompe o asfalto.

Façam completo silêncio, paralisem os negócios,

garanto que uma flor nasceu.

Sua cor não se percebe.

Suas pétalas não se abrem.

Seu nome não está nos livros.

É feia. Mas é realmente uma flor.

Sento-me no chão da capital do país às cinco horas da tarde

e lentamente passo a mão nessa forma insegura.

Do lado das montanhas, nuvens maciças avolumam-se.

Pequenos pontos brancos movem-se no mar, galinhas em pânico.

É feia. Mas é uma flor. Furou o asfalto, o tédio, o nojo e o ódio. (DRUMMOND, 1945, pp. 13-14)

Por meio de uma abordagem com elementos de reflexão filosófica, não esperamos macular a natureza lírica da expressão poética, mas fecundar um pensamento que já é expresso em sua totalidade; cremos que o poema por si só está imerso na reflexão filosófica. Defendemos como Seabra (2014) que o poema deve ser lido como uma filosofia altamente condensada e, enquanto discurso filosófico, como um poema extremamente dilatado. Para fazer jus a esta abordagem, além de pontos semelhantes, visamos à criação de uma tensão entre duas dimensões que se cruzam e que dinamicamente se fecundam.

Benedito Nunes em Poesia e Filosofia: uma transa defenderá a relação entre filosofia e literatura pelo modelo transicional. Nesta perspectiva, a literatura não se resume a título de exemplificação ou imagem condensada de um argumento filosófico, mas a encarar o limite intransponível da expressão poética frente à reflexão filosófica. Assim, busca-se a intermediação do conceito não para argumentá-lo por um processo lógico, mas para fecundá-lo naquilo que o revela à medida que transita no campo da linguagem entre o objetivo e o subjetivo, ou seja, em um hiato dialógico. De acordo com Nunes:

É desta relação transacional que vamos nos ocupar agora, com o cuidado de não tomar o poeta-filósofo como entidade pessoal, posta no mostruário dos profissionais da inteligência, caso em que a inteligência combinaria o intuitivo com o conceptual de forma imprevisível. (NUNES, 2009, p. 29)

Em comentário a Heidegger, Nunes nota o surgimento do poema como campo que manifesta o ser, doando à palavra a tensão de significado revelador:

Então a linguagem é a linguagem de todos e de ninguém, gastas pelo consumo, manejáveis pelo seu valor de troca no mercado das significações estabilizadas que a gente negocia, convertidas na gestualística verbal do falatório, da parolagem, as palavras fecha-nos o mundo. E só poderá novamente reabri-lo o discurso, se reavivado pelo seu tom, pela disposição que o abre ao mundo e o qualifica de poético: "a comunicação das possibilidades existenciais da disposição, ou seja, da abertura da existência, pode tornar-se a meta explicita do discurso poético". (NUNES, 2016, p. 122)

Milan Kundera em $A$ arte do Romance notara que o gênero do romance europeu dá-se como fonte de conhecimento de uma realidade até então inexplorada pela 
filosofia. Em certa medida, gostaríamos de remeter-nos a esta análise, aplicando-a à própria experiência da poesia e prosa brasileiras:

Efetivamente, todos os grandes temas existenciais que Heidegger analisa em Ser e tempo, julgando-os abandonados por toda a filosofia européia anterior, foram desvendados, mostrados, esclarecidos por quatro séculos de romance (quatro séculos de reencarnação européia do romance). Um por um, o romance descobriu, à sua própria maneira, por-sua própria lógica, os diferentes aspectos da existência. (KUNDERA, 2009, p. 12)

Em distinção à experiência literária brasileira, o professor Paulo Margutti argumenta que o desenvolvimento da filosofia no Brasil fora incorporado melhor na literatura, carregando uma reflexão filosófica autêntica a despeito da exegese das academias.

No Brasil as obras literárias com víeis filosófico são, de um modo geral, mais elaboradas e mais profundas do que as obras filosóficas propriamente ditas. Estas últimas, na maior parte dos casos, estão voltadas para o comentário exegético de pensadores estrangeiros. Quando elas tentam oferecer alguma contribuição pessoal, geralmente não conseguem atingir o mesmo grau de elaboração e profundidade de que o literato filósofo é capaz. (MARGUTTI, 2011, p. 14)

Ao tentarmos aproximar os textos literários de uma leitura filosófica, preferimos uma abordagem de interfaces entre o poema a flor e a náusea e a concepção de diálogo de Martin Buber, trazendo à tona, com isso, uma dimensão que cremos fecundar a poesia drummondiana, inclusive trazendo luz à forma própria da experiência artística brasileira contemporânea quando esta adentra o terreno do mítico.

Cremos que Buber representa um pensamento que tenha eco na sensibilidade da experiência filosófico-literária brasileira por possuir uma caraterística a que gostaríamos de chamar "pós-religiosa", que abandona a matriz religiosa tradicional, porém resgata o religioso numa dimensão inteiramente nova de mistério. Buber, assim, alinha-se às leituras heterodoxas, como Kierkegaard, Feuerbach e Nietzsche, oferecendo-nos uma nova leitura, sobretudo apelando à existência de uma forma diversa a partir destes autores clássicos. Além do mais, Buber é porta-voz de uma cultura e serve como exemplo de filósofo judeu que pensou seu tempo sem ser absorvido pela pura exegese da filosofia clássica ocidental, embora dela faça um uso.

A obra de Martin Buber é um misto entre literatura e filosofia, cujos exemplos dão-se nos livros Daniel (1913) e Moises (1958), fazendo-se exemplos de obras literárias com traços eminentemente filosóficos que têm origem tanto no judaísmo como na própria filosofia clássica. A transcrição dos textos hassídicos e a tradução da Bíblia do hebraico ao alemão também são trabalhos onde Buber aprofunda-se na percepção de sua cultura ao reconstruir o núcleo da mensagem judaica em um tempo fortemente deteriorado de fé (SCHOLEM, 1994). Sua obra traz uma reflexão não sistemática que interliga filosofia e a mística sabedoria judaica.

O radical da experiência religiosa que Buber encontra no judaísmo permite-lhe sustentar uma filosofia ímpar. Com isso, compreendemos que a aproximação entre Buber e Drummond faz-se em um nível mais intuitivo do que analítico. A interface aqui proposta está compreendida na filosofia do dialógico de Martin Buber, para o qual a condição humana mais elementar é a relação. Em A flor e a náusea a relação dá-se entre o sujeito lírico e a rosa no afinamento de uma náusea: "Uma flor nasceu na rua!/ Passem de longe, bondes, ônibus, rio de aço do tráfego" (DRUMMOND, 1945, p. 14).

\footnotetext{
${ }^{1}$ Vale ressaltar que a flor de $A$ flor e a náusea conjuga-se na perspectiva moderna no que tange à poética que tem como clave o estranhamento e as imagens profundamente ligadas ao choque moderno, como sublinha Hugo Friedrich em A estrutura da lírica moderna: da metade do século XIX a meados do século XX: "Quando a poesia moderna se refere a conteúdos- das coisas e dos homens- não as trata descritivamente, nem com o calor de um sentir íntimos. Ela nos conduz ao âmbito do não familiar, torna-os estranhos, deforma-os. A poesia não quer
} 
Para o filosofo judeu há duas atitudes fundamentais do homem no mundo, manifestas em duas palavras-princípio: Eu-Tu e Eu-Isso, a primeira é a palavra da presença: Eu-tu, onde o homem está na relação com a alteridade e com a integridade de seu ser. A segunda é a palavra de objetificação: Eu-isso, onde a relação é parcial e reduzida às formas de operação do poder.

As palavras-princípio são proferidas pelo ser.

Se se diz tu profere-se também o eu da palavra principio Eu-Tu.

Se se diz isso profere-se também o eu da palavra principio Eu-isso.

A palavra-princípio Eu-tu só pode ser proferida pelo ser na sua totalidade.

Palavra-princípio eu-isso não pode jamais ser proferida pelo ser em sua totalidade.

(BUBER, 2008, p. 51)

Lançando mão desses princípios, Buber compreende o encontro como presença ou ausência do homem na relação, a qualidade dessa presença define-se pela distância ou proximidade do Tu ou do Isso. Proferir a palavra-princípio Eu-Tu é responder ao chamado; estar ou não presente significa acolher ou fugir da relação.

Na ontologia buberiana, o encontrar fundamenta-se no espaço do Tu. A exploração filosófica do campo do encontro geraria, por assim dizer, uma protocategoria antropológica melhor descrita pela poesia e literatura, onde o poeta recriaria no campo da linguagem a tensão do contato, resultado do encontro com o Tu. Assim, a consciência do mundo vem do vínculo da linguagem com o Tu à medida que cria no espaço e no tempo uma resposta. A literatura por excelência é a uma tentativa de resposta ou, mais precisamente, uma perspectiva de diálogo.

É de interesse notar que Buber descreve o antropólogo na figura do escritor, que realiza um trabalho entre a experiência e a memória:

O antropólogo, portanto tem que resistir a qualquer intenção de permanecer fora com seu eu observador e, quando lhe sobrevier a cólera, não a perturbar convertendo-se em seu espectador, senão que a abandona a seu curso sem o empenho de ganhar sobre ela uma perspectiva. Será capaz de registrar na recordação o que sentiu e fez até então; para ele, a memoria ocupa o lugar de experimentar consigo mesmo. Mas o mesmo que os grandes escritores, em seu trato com os demais homens, não registram deliberadamente suas peculiaridades, tomando como se disséssemos, notas invisíveis, senão que tratam com elas de uma forma natural e não inibida, deixando a colheita para a hora da colheita. (BUBER, 1960, pp. 22-23)

Em sua tentativa de exploração do mundo, Drummond opera um trabalho do mesmo nível antropológico descrito por Buber, adentrando a esfera das relações. Entre ausência e presença, o poeta vai ao campo do inter-humano, angustiado e inquieto, na busca ansiosa e com "sede infinita", porém nada encontra senão a si mesmo como um mito ou, de outro modo, depara-se com ilhas de pureza indescritível, num campo onde a palavra transborda para o nível do silêncio intuitivo. Em $A$ flor e a náusea poder-se-á verificar o silêncio que se transborda de um sentido para além da realidade concreta, instalando-se na complexidade que se intercruza no pensamento:

\footnotetext{
"Sento-me no chão da capital do país às cinco horas da tarde/ e lentamente passo a mão nessa forma insegura. / Do lado das montanhas, as nuvens maciças avolumam-se. Pequenos pontos brancos movem-se no mar, galinhas em pânico. É feia. Mas é uma flor. Furou o asfalto, o tédio, o nojo e o ódio". (DRUMMOND, 1945, p. 14, grifo nosso)
}

mais ser medida em base ao que comumente chama realidade, mesmo se- como ponto de partida para sua liberdade- absorveu-a com alguns resíduos. A realidade desprendeu-se da ordem espacial, temporal, objetiva e anímica e subtraiu as distinções- repudiadas como prejudiciais- que são necessárias a uma orientação normal do universo: as distinções entre o belo, o feio, entre a proximidade e a distância, entre a luz e a sombra, entre a dor e a alegria, entre a terra e o céu" (FRIEDRICH, 1978, pp. 16-17). 
A náusea, tão conhecida na literatura sartreana como sinônimo da liberdade que promove a abertura ao cru da existência, é substituída em Drummond pela incapacidade de reconhecer-se nas representações de seu tempo: "Em vão me tento explicar, os muros são surdos./ Sob a pele das palavras há cifras e códigos." (Idem, p.13). E adiante a condenação do mundo reificado: "Todos os homens voltam para casa. Estão menos livres, mas levam jornais e soletram o mundo, sabendo que o perdem." (Ibidem).

A denúncia do mundo estéril repete-se em outros poemas, como é o caso do Em nosso tempo: "As leis não bastam. Os lírios não nascem da lei.", e no poema elegia 1838: "trabalhas sem alegria para um mundo caduco/ onde as formas e as ações não encerram nenhum exemplo." Trazendo à tona a amargura de um mundo em dissolução que, com efeito, carece dos sentidos originais e das formas orgânicas do espírito, o fracasso do poeta e o fracasso do tempo não deixam de testemunhar a nostalgia reprimida.

Por outro lado, a solidão é um sentimento agônico do poeta sobrevindo ao real com uma fantasia de desejo, porém, mesmo aí a solidão não se encerra sem si mesma, não resolve a si mesma. Mesmo quando fantasia, ela é expectante, apaixonada: sobre tal característica trazemos uma breve nota de Buber:

Acaso poderia argumentar que a lírica significa semelhante perfeição e transfiguração da relação do homem consigo mesmo. mas , pelo contrário, representa a poderosa negação da alma a encontra satisfação no contato consigo mesma. O poema nos diz que a alma, até nos casos em que se demora consigo mesma, não pensa em si mesma, senão no ser que não é ela mesma, e que o ser que não é ela mesma a visita em seu ninho, a comove e lhe satisfaz. (BUBER, 1960, p. 111)

A poesia drummondiana, especialmente em Aflor e a náusea, não deixa de seguir o itinerário do ôntico ao antológico perpassando pelo tédio, angústia, expectativa e pelo encontro. No entanto, é neste último que o mistério se condensa, isto é, o encontro do poeta com a flor, a nova forma desprezada, estranha aos olhos, "Feia. Mas uma flor" (DRUMMOND, 1945, p. 14), nascendo da fenda do asfalto. Entrevemos aqui o encontro com o Tu presentificado, onde o diálogo realiza-se no "contato misterioso" com essa forma delicada, que transborda o campo do signo, como é possível ler-se nos versos seguintes: "Sua cor não se percebe./ Suas pétalas não se abrem. Seu nome não está nos livros./ É feia. Mas é realmente uma flor" (Ibidem).

A percepção da tensão entre palavra e coisa opera na tentativa de representação da experiência, mas é sempre contraposta com a angústia e o sentimento de fracasso do sujeito lírico, obtendo fugazes momentos de um tipo de fé. Concordamos com John Gledson em Poesia e poética de Carlos Drummond Andrade, ao notar a fé como elemento presente na escrita drummondiana:

Em termos filosóficos, mostra que este Drummond cético é uma espécie de kantiano- “o recurso de Kant e da poesia é verso iônico mas sugestivo deste livro central. Privado de explicações religiosas da existência, não obstante chega a uma espécie de fé. É uma fé, sobretudo, na possibilidade de uma humanidade comum, apesar da fragmentação que o mundo moderno nos impõe, e que se evidencia na arte e na poesia em particular. (GLEDSON, 2018 , p. 20)

A justa percepção da privação que Drummond faz da explicação religiosa para desenvolver uma espécie de fé é, aqui, sinal da abertura da poética ao outro e ao mistério; contrastando com o desespero, a flor é ao mesmo tempo concreta e impalpável. Nela o poeta promove não a unidade permanente, mas o elã de diálogo, ou, precisamente, o despertar da interioridade na abertura ao mistério e ao Tu-eterno.

Essa abertura ao outro e à alteridade absoluta manifesta na ânsia, põe o poeta na insegurança de estar comunicando ou iludindo. O eu lírico assume, então, uma experiência autofágica levada à incerteza de si mesmo e da realidade como um todo. 
Assim, a modernidade, que emplaca a degeneração do mundo, traz à consciência do poeta a ferida recalcada do eu na incapacidade de síntese como elemento de formação que oscila entre o Eu e a alteridade frustrada: "Olhos sujos no relógio da torre:/ Não, o tempo não chegou de completa justiça. / O tempo éainda de fezes, maus poemas, alucinações e espera" (DRUMMOND, 1945, p. 13, grifo nosso).

Outro aspecto é a consciência da impossibilidade da perpetuação da imagem poética; "os maus poemas", a "precária síntese" empregadas por Drummond, representando-as no esforço de comunicar-se em um mundo tumultuado, ele se vê diante da "fugitiva imagem", uma pálida forma de vida, um acontecimento facilmente ignorado sem a pretensão de abarcar a experiência em sua completude, como sublinha o sujeito lírico: "Em vão tento explicar,/ os muros são surdos./ Sob a pele das palavras há cifras e códigos" (Ibidem). Temos aqui uma experiência que vacila entre o ceticismo e a esperança realizadora. Aqui se reconhece o ponto que a perspectiva Buberiana inaugura: é o espaço do "entre", que, do ponto de vista lírico, é o chamado, uma espécie de metapoesia que insinua a liberdade na abertura à reciprocidade.

Do "entre" do diálogo, entre o poeta e o "mundo nu", emerge o ente da forma, na dimensão que faz surgir o "mistério do contato". O acontecimento é vivenciado e sua visão contemplada na própria originalidade do não redutível que ao poeta cabe apenas sugerir, como sublinha Buber: "o essencial do acontecimento não é que o outro um faça do outro seu objeto, mas o fato que ele não consegue fazê-lo e a razão de seu insucesso." (BUBER, 2006, p. 138).

Dessa forma, o poema A flor e a náusea revela o supremo anseio de organicidade, onde o "pathos dialético" é abandonado em favor de um "pathos dialógico". Esse estado de coisas aparece como força apolítica, anarquizador e insurgente do poeta, o qual, mesmo nauseado, encontra o solo fecundo para a vida verdadeira, além de todo o vazio estético. Assim, o eu lírico declara o melhor de si ao ligar-se ao viés do ódio, mas ao mesmo tempo conjugado na salvação de si mesmo: "Pôr fogo em tudo, inclusive em mim./ Ao menino de 1918 chamavam anarquista./ Porém meu ódio é o melhor de mim./ Com ele me salvo/ e dou a poucos uma esperança mínima ${ }^{2 \prime}$ (DRUMMOND, 1945, p. 14).

Em suas reflexões, Buber descreve acontecimentos pessoais onde o filósofo reconhece os momentos legítimos de diálogo; neles percebemos o mesmo sentimento de tentativa de dissolução das velhas formas no mergulho no espaço do encontro:

Na angústia mortal de um refúgio antibombas, os olhares dos desconhecidos tropeçam alguns instantes, e uma reciprocidade surpreendente e sem engate, quando ao soar da sirene que anuncia o cessar do alarme, aquilo fica esquecido e, no entanto 'ocorreu' em um âmbito não maior que aquele momento. Nas salas à escuras, se estabelece entre os ouvintes, desconhecidos, impressionados a mesma pureza e a mesma intensidade por uma melodia de Mozart, uma relação apenas perceptível e, contudo, elementarmente dialógica, que quando se ascende as luzes apenas se se recorda. (BUBER, 1960, pp. 148-149)

A descoberta da flor em Drummond, portanto, recolhe-se da multidão para recolher do mundo o que não pode ser esquecido. Seu encontro não pode ser lido como ilusão. O elemento mítico é aqui uma ligação ao Tu de todas as coisas; diríamos que não foi o bombardeio que levou os desconhecidos a criarem um espaço de ilusão, mas, na superação do irreal opressivo, fora a fantasia que transformou o irreal em reciprocidade, permitindo-se o encontro na realidade daquilo que é. Destaca-se a dinâmica que a ausência e a presença fazem surgir na nova forma.

2 “Mas toda grande poesia não destila um veneno, que é, ao mesmo tempo, antídoto e remédio? Não é o poeta, e sobretudo, um poeta que conhece o poder de recusa e de desprezo da palavra escrita, aquele que assume a função do pharmacon" (NUNES, 2009, p. 239). 
A brevidade do acontecimento, a quase insignificância da flor é o modo de ser da presença: ele é breve porque é sentido apenas na linguagem após sair da relação imediata. Em Buber, o instante é atemporal e inespacial, configurando-se somente pela força do ego, na resposta, na qual o homem retorna ao mundo do Isso, trazendo consigo um sentimento nostálgico, uma impressão. A fissura do real cotidiano torna-se a fissura ao real do ser revelado na atualidade da presença, de modo que o encontro, por isso, não pode ser descrito, não pode ser comunicado, não pode ser objetificado, explicando-se, portanto, como característica de mistério.

Vemos em A rosa do povo outro poema com a mesma característica nostálgica: O elefante. O poema traz uma imagem coberta por ironia, e o preparo do poeta que peregrina no mundo em busca de experiências originais endossa a nostalgia reprimida. O corpo irônico na busca do encontro tornar-se-á a tônica da fabricação, o percurso é externamente o desmonte do ego, reflexo da ânsia pelo encontro, e a expectativa de vida autêntica. A relação interior do poeta é embalsamada pela paixão e angústia, tornando a solidão um preparo, como se lê nos trechos seguintes: "Fabrico um elefante/ de meus poucos recursos./ Um tanto de madeira/ tirado a velhos móveis/ talvez me dê apoio" (DRUMMOND, 1945, p. 95).

Vemos aqui a categoria religiosa na esquiva das imagens vazias do tempo, talvez como uma categoria de conversão para a atualidade do homem através do indivíduo: "Se a lembrança de sua decadência, de seu eu inatual e de seu eu atual, permitir alcançar a raiz profunda que o homem chama desespero e de onde brotam a autodestruição e a degeneração, isto já seria o início da conversão" (BUBER, 2009, p. 89).

A categoria religiosa ocorre aqui como um radical do diálogo entre a busca do eterno e a finitude do próprio homem. Sentida com uma presença, pressentida e restaurada na própria imanência do mundo pelo encontro. Essa espécie de intuição, que é irmanada nos homens através da liberdade estética, ganha o peso de uma responsabilidade que surge da possibilidade de diálogo que é: a não objetificação.

A superação do mundo fragmentado, portanto, não advém propriamente do operar as palavras puras, mas do estado que subverte as palavras da representação ao ser, como um apontar sempre atualizado na relação do indivíduo com o Tu, seja numa flor, seja numa pedra, sempre como perspectivas que intuem o Tu-eterno e nele se fundamentam, comprovado pelo mote do poema: "É feia. Mas é uma flor" (DRUMMOND, 1945, p. 14).

\section{Considerações finais}

A relação da filosofia com a realidade não é apenas de ordem da tradução dos conflitos humanos no ambiente cultural, assim como o desvelar do ser não se dá somente na procura, no interior da produção literária brasileira, de aspectos que sejam relevantes à filosofia: sua relutância ou instância é pelo reconhecimento de um âmbito de problemas integralmente concebido na imanência do indivíduo na cultura; este âmbito também é o único capaz de responder à altura e com integridade as demandas do espírito.

O alvorecer de uma produção filosófica na literatura apresenta padrões culturais que se propõem com força própria, com expressões imanadas de nosso próprio espaço linguístico. Não obstante, a literatura clama por um novo trato epistemológico capaz de refletir as intuições e nuances que marcam as imagens "incendiárias" e altamente condensadas da poesia e prosa brasileiras.

Fazendo a interface entre Buber e Drummond, dois "filósofos-poetas", gostaríamos de sugerir à fundamentada crítica o reconhecimento da presença de uma expressão ôntico- poética que possui eloquência própria, não apenas redescobrindo nas palavras sentidos universais, mas sinalizando um espaço vivo de experiências que não se dão 
ao entendimento de maneira acabada, sugerindo que esta reflexão é e se conforma a um tipo de "Pathos dialógico", isto é, um discurso lírico construído na relação com a alteridade.

Correspondência: Universidade Estadual do Amapá - UEAP. Av. Duque de Caxias, 60. Campus Graziela. Centro. Macapá - AP - Brasil. CEP: 68900-071. E-mail: fabricio.lemos1987@yahoo.com.br / E-mail: brunojbr10@hotmail.com.

Apoio financeiro: Nenhum

Conflito de interesses: Nenhum.

Todos os autores leram e aprovam a versão final submetida à revista Em curso. 


\section{Referências bibliográficas:}

ANDRADE, C. D. A Rosa do povo. São Paulo: Círculo do Livro, 1945.

BUBER, M. Eu e tu. 10 a ed. São Paulo: Centauro, 2006.

Qué es el hombre. Buenos Aires: Fondo de Cultura Economica, 1960.

Sobre comunidade. São Paulo: Perspectiva, 2008.

Do diálogo e do dialógico. São Paulo: Perspectiva, 2014.

FRIEDRICH, H. Estrutura da lírica moderna: da metade do século XIX a meados do século XX. São Paulo: Duas Cidades, 1978.

GLEDSON, J. Poesia e poética de Carlos Drummond de Andrade. 2a ed., e-galáxia, 2018. (Edição digital). SCHOLEM, G. O Golem, Benjamin, Buber e outros justos: judaica I. São Paulo: Perspectiva, 1994.

MARGUTTI, P. R. Apresentação. In: ALMEIDA, M. M. Um deus no tempo ou um tempo cheio de deus. São Paulo: Loyola, 2011.

NUNES, B. Heidegger. São Paulo: Loyola, 2016.

Carlos Drummond de Andrade. In: PINHEIRO, V. S. (Org.). A clave do poético. São Paulo: Companhia das Letras, 2009.

Poesia e Filosofia: uma transa. In: ROHDEN, L.; PIRES, C. (Orgs.). Filosofia e Literatura: uma relação transacional. Ijuí: Editora Unijuí, 2009.

ZUBEN, N. A. V. Martin Buber: cumplicidade e diálogo. São Paulo: Edusc, 2003.

KUNDERA, M. Arte do romance. São Paulo: Companhia de Bolso, 2009.

Recebido em: 25/Mai/2018 - Aceito em: 30/Out/2018. 